\title{
TRATAMENTO DE BANHOS DE TINGIMENTO TÊXTIL POR PROCESSOS FOTO-FENTON E AVALIAÇÃO DA POTENCIALIDADE DE REUSO
}

\author{
Geovani Zanella, Mauro Scharf e Giovana Aparecida Vieira \\ Departamento de Química, Fundação Universidade Regional de Blumenau, 89012-900 Blumenau - SC, Brasil \\ Patricio Peralta-Zamora* \\ Departamento de Química, Universidade Federal do Paraná, CP 19081, 81531-980 Curitiba - PR, Brasil
}

Recebido em 16/6/09; aceito em 18/12/09; publicado na web em 8/4/10

\begin{abstract}
TREATMENT OF TEXTILE DYEING BATHS BY PHOTO-FENTON PROCESSES AND EVALUATION OF THE REUSE POTENTIALITY. In this work the treatment of textile dyeing baths by a sequential reductive-oxidative process was evaluated, aiming its utilization in new dyeing process. The results demonstrated that reactive dyes can be easily degraded by reductive processes mediated by zero-valent iron, a fact that induces decolorizations of about $80 \%$. Sequential photo-Fenton processes permit almost total removal of the residual color with elimination of $90 \%$ of the COD content. The reuse of treated residues permits the achievement of materials that attend practically all textile specifications, with exception of the color difference parameter $(\Delta \mathrm{E})$, which is unsatisfactory toward the importation standards, but adequate for the national market.
\end{abstract}

Keywords: dyeing; photo-Fenton; reuse.

\section{INTRODUÇÃO}

Nas últimas décadas, o fenômeno de contaminação ambiental alcançou proporções globais, afetando o delicado balanço de muitos sistemas ecológicos. Dentro deste contexto, deve ser dado especial destaque à sistemática contaminação das águas naturais, compartimentos que historicamente têm servido de vertedouro para uma grande variedade de resíduos domésticos e industriais.

Em função das pessimistas projeções relacionadas com a disponibilidade de água, a legislação tem se tornado cada vez mais restritiva, evoluindo continuamente no estabelecimento de padrões específicos para o enquadramento de corpos de água, assim como de condições e padrões para o lançamento de efluentes (Resoluções CONAMA $357 / 2005$ e 396/2008).

No contexto industrial, a incorporação de práticas que permitam o reuso da água se torna cada vez mais urgente, não apenas para satisfazer as imposições da legislação, mas também para diminuir o seu consumo e reduzir os custos de produção. ${ }^{1,2}$ Esta necessidade se mostra especialmente importante na área de beneficiamento têxtil, na qual o consumo médio de água costuma alcançar valores da ordem de $160 \mathrm{~m}^{3}$ por tonelada de fibra processada, ${ }^{3}$ principalmente em função de operações de branqueamento, mercerização, tingimento e lavagem. ${ }^{4}$

Os efluentes líquidos produzidos pela atividade têxtil se caracterizam por apresentar elevada carga orgânica, alta concentração de sais e forte coloração, esta última característica associada à presença de corantes residuais. Em geral, estima-se que 15 a $50 \%$ da carga de corantes pode ser perdida nas etapas de tingimento e lavagem, ${ }^{5,6}$ o que torna evidente a necessidade de sistemas adequados de tratamento. Infelizmente, uma importante parcela destes corantes se mostra recalcitrante frente a processos biológicos convencionais, mesmo utilizando-se rotinas anaeróbias-aeróbias sequenciais. ${ }^{7}$

Em função das deficiências apresentadas pelos sistemas convencionais de tratamento, usualmente representados por processos biológicos e de coagulação química, ${ }^{8}$ novas alternativas de tratamento têm sido regularmente propostas. Dentro do contexto do reuso dos efluentes têxteis é possível destacar a associação de processos

\footnotetext{
*e-mail: zamora@quimica.ufpr.br
}

biológicos com processos de ultra ${ }^{9}$ e nanofiltração, ${ }^{10}$ a utilização de processos de oxidação eletroquímica ${ }^{11} \mathrm{e}$, menos frequentemente, o uso de rotinas envolvendo processos físico-químicos, biológicos e de adsorção em carvão ativado. ${ }^{12}$

Embora muitos trabalhos atestem uma elevada capacidade dos processos Fenton em relação à remediação de efluentes têxteis contendo corantes, ${ }^{13-16}$ poucos estudos tratam da utilização destes processos em rotinas que permitam o reuso dos efluentes em questão. ${ }^{17-19}$ Em geral, os poucos estudos realizados demonstram que o reuso dos efluentes somente é possível quando os processos Fenton são complementados com processos de troca iônica, ${ }^{17}$ filtração em membrana, ${ }^{18}$ ou coagulação química. ${ }^{19}$

Por sua vez, vários trabalhos demonstram a elevada eficiência de degradação de sistemas redutivos fundamentados no uso de ferro metálico ${ }^{20}$ e de sistemas Fenton aplicados na presença de ferro metálico, ${ }^{21}$ em relação à degradação de azo-corantes. Entretanto, poucos trabalhos relatam o tratamento de efluentes de tingimento e muito menos o desenvolvimento de rotinas de tratamento que viabilizem o reuso.

Neste trabalho, a potencialidade da associação de processos redutivos (mediados por ferro metálico) e oxidativos avançados (fotoFenton) foi avaliada, em relação ao tratamento e reuso de efluentes de tingimento de fibras de algodão.

\section{PARTE EXPERIMENTAL}

\section{Reagentes}

Os corantes reativos amarelo intracom 3RL (C.I. 145, Yokcheire), vermelho intracom 3 SR (C.I. 195, Yokcheire) e preto reativo 5 (C.I. 20505, Dyestar) foram gentilmente fornecidos pela Siderquímica, em grau técnico de pureza. As suas estruturas químicas são apresentadas na Figura 1.

Os auxiliares de tingimento - $\mathrm{NaOH}$ (50\%, Buchle Lepper), $\mathrm{Na}_{2} \mathrm{CO}_{3}(70 \%$, Vetec), $\mathrm{NaCl}(99,99 \%$, Vetec), Sidertex SQ 70 (sequestrante aniônico), Sidertex EG 97 (emulgrador), Sidertex DS 208 (dispersante), Sidertex NZ 130 (redutor), Sidertex EB 89 (detergente), Sidertex EB 82 (tensoativo) e Sidertex FX 305 (fixador) - foram gentilmente fornecidos pela Siderquímica (São José dos Pinhais - PR). 

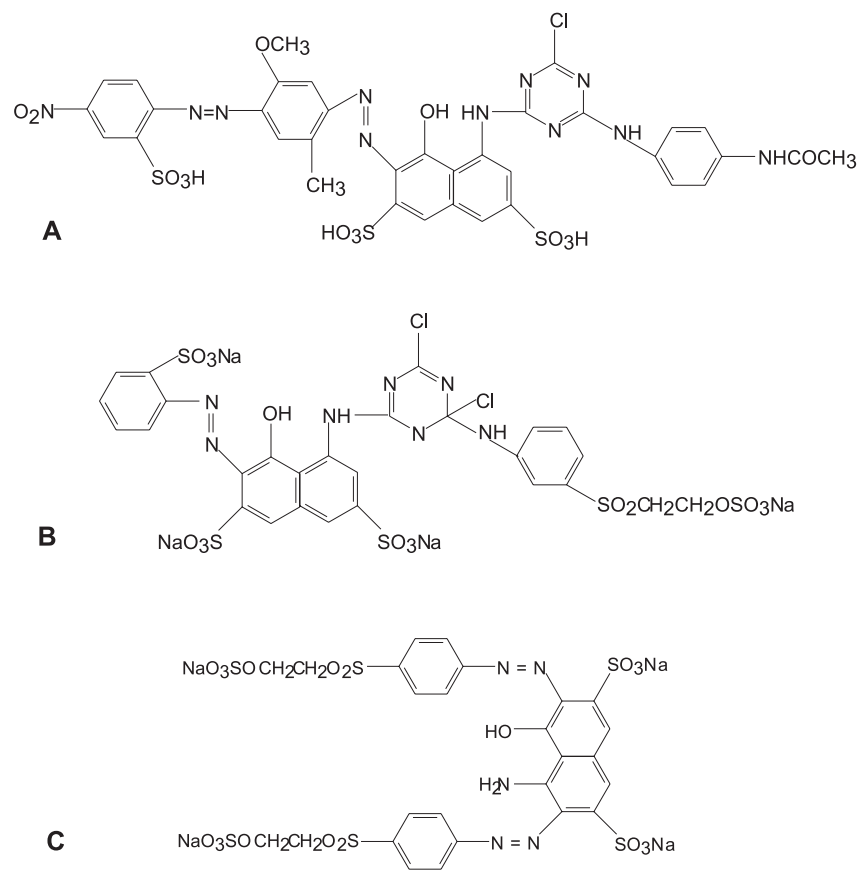

Figura 1. Estrutura química dos corantes amarelo intracom $3 R L(A)$, vermelho intracom $3 S R(B)$ e preto Reativo $5(C)$

Peróxido de hidrogênio (Peróxidos do Brasil, $50 \% \mathrm{~m} / \mathrm{m}$ ) foi utilizado como recebido, sendo conservado sob refrigeração. A sua concentração foi verificada periodicamente por titulação permanganométrica.

Como fonte de ferro metálico foi utilizada lã de aço comercial (Assolan), constituída por fibras de aproximadamente $0,06 \mathrm{~mm}$ de diâmetro e teor de ferro de cerca de $99 \%$ (m/m). Objetivando-se retirar óxidos que depositam na sua superfície, as fibras foram previamente lavadas com solução aquosa de $\mathrm{H}_{2} \mathrm{SO}_{4}(10 \% \mathrm{v} / \mathrm{v})$.

Outros reagentes (ácidos, bases e sais) foram de grau analítico P.A.

\section{Estudos preliminares}

A eficiência de degradação apresentada pelo processo redutivo foi preliminarmente avaliada em relação à degradação de um corante padrão (preto reativo 5), utilizado em concentração de $20 \mathrm{mg} \mathrm{L}^{-1}$. Nestes estudos foram avaliados os efeitos do $\mathrm{pH}$, da vazão de alimentação e da espessura das fibras de palha de aço, monitorando-se a degradação do corante e a geração de formas solúveis de ferro. Posteriormente, a eficiência do processo oxidativo foi também avaliada, levando-se em consideração a degradação do substrato modelo.

Em ambos os casos foram utilizadas as condições de tratamento descritas no item Tratamento dos banhos.

\section{Tingimento dos tecidos}

Operações de tingimento foram realizadas em malha $100 \%$ algodão, com gramatura de $1,94 \mathrm{~g} \mathrm{~cm}^{-2}$.

Inicialmente, a malha foi submetida ao processo de purga, que objetiva a remoção de impurezas naturais e o aumento da afinidade da fibra pelos corantes. Com este propósito, a malha foi deixada em contato com uma solução contendo $\mathrm{NaOH}\left(1,5 \mathrm{~g} \mathrm{~L}^{-1}\right)$, Sidertex SQ $70\left(1,0 \mathrm{~g} \mathrm{~L}^{-1}\right)$ e Sidertex EG $97\left(1 \mathrm{~g} \mathrm{~L}^{-1}\right)$, durante 30 min a $95{ }^{\circ} \mathrm{C}$. Posteriormente, a malha foi lavada com água à fervura, objetivandose a remoção de gorduras, ceras e óleos previamente saponificados. Finalmente, a malha foi submetida à lavagem com solução aquosa de ácido acético $\left(3 \mathrm{~mol} \mathrm{~L}^{-1}\right)$, de maneira a recuperar a sua neutralidade.
Os tingimentos foram realizados em triplicata, utilizando-se 126 $\mathrm{g}$ de tecido e $1 \mathrm{~L}$ de banho (relação de banho 1:8), este último constituído de: Sidertex DS $208\left(1,5 \mathrm{~g} \mathrm{~L}^{-1}\right)$, Sidertex NZ $130\left(0,2 \mathrm{~g} \mathrm{~L}^{-1}\right)$, $\mathrm{Na}_{2} \mathrm{CO}_{3}\left(5,15 \mathrm{~g} \mathrm{~L}^{-1}\right), \mathrm{NaCl}\left(60 \mathrm{~g} \mathrm{~L}^{-1}\right), \mathrm{NaOH}\left(1 \mathrm{~g} \mathrm{~L}^{-1}\right)$ e os corantes reativos amarelo intracom $3 \mathrm{RL}(1,1 \% \mathrm{~m} / \mathrm{v})$, vermelho intracom $3 \mathrm{SR}$ $(0,50 \% \mathrm{~m} / \mathrm{v})$ e preto reativo $5(0,44 \% \mathrm{~m} / \mathrm{v})$. O processo foi realizado a $60{ }^{\circ} \mathrm{C}$ por $90 \mathrm{~min}$, em $\mathrm{pH} 10,5$.

Após o tingimento, a malha foi lavada com água corrente e, posteriormente, por imersão em solução de ácido acético $\left(3 \mathrm{~mol} \mathrm{~L}^{-1}\right)$ e Sidertex EB $82\left(2,0 \mathrm{~g} \mathrm{~L}^{-1}\right)$. Finalmente, a fixação foi promovida por imersão da malha tingida em solução aquosa contendo Sidertex FX $305(2,5 \% \mathrm{~m} / \mathrm{v})$.

Todas as operações de tingimento e lavagem foram realizadas em máquina de tingimento Mathis, modelo ALT 1.

\section{Tratamento dos banhos}

Após o processo de tingimento, os banhos exauridos (sem nenhuma diluição) foram tratados pelo processo redutivo, utilizando-se um sistema contínuo. Este sistema é formado por uma coluna de vidro de $26 \mathrm{~cm}$ de altura, $2,5 \mathrm{~cm}$ de diâmetro interno e volume útil de aproximadamente $100 \mathrm{~mL}$, recheada com $14 \mathrm{~g}$ de lã de aço comercial. A amostra de banho (3 L) teve o seu pH ajustado com solução aquosa diluída de $\mathrm{H}_{2} \mathrm{SO}_{4}$ (pH 3), sendo passada através da coluna com vazão de $15 \mathrm{~mL}$ min $^{-1}$ (tempo de retenção de aproximadamente 6 min) com auxílio de uma bomba peristáltica Provitec (modelo DM 5000). As amostras foram coletadas em intervalos regulares, filtradas em membrana de acetato de celulose $(0,45 \mu \mathrm{m})$ e submetidas a controle analítico.

Posteriormente, as amostras reduzidas foram adicionadas de peróxido de hidrogênio (concentração final de $100 \mathrm{mg} \mathrm{L}^{-1}$ ) e submetidas ao processo foto-Fenton. Este processo foi aplicado em reator de vidro de $200 \mathrm{~mL}$ de capacidade, equipado com camisa para refrigeração por água e sistema de agitação magnética. A radiação foi proporcionada por uma lâmpada a vapor de mercúrio de $125 \mathrm{~W}$, inserida na solução com ajuda de um bulbo de vidro Pyrex. As amostras foram coletadas em intervalos regulares, precipitando-se o ferro por adição de solução aquosa de $\mathrm{NaOH}(\mathrm{pH} \approx 12)$. Posteriormente, as amostras foram filtradas em membrana de acetato de celulose $(0,45 \mu \mathrm{m})$ e submetidas a controle analítico.

\section{Reuso dos banhos tratados}

Após tratamento pelo processo proposto, a água residual foi utilizada em novos processos de tingimento, os quais foram aplicados nas condições descritas a seguir.

Tingimento padrão: realizado com água destilada e seguindo-se a receita de tingimento da indústria.

Reuso 1: realizado com água tratada pelo processo proposto, adicionada de todos os auxiliares de tingimento indicados na receita original.

Reuso 2: realizado com água tratada pelo processo proposto, adicionada de todos os auxiliares de tingimento indicados na receita original, com exceção de $\mathrm{Na}_{2} \mathrm{CO}_{3}$ e $\mathrm{NaCl}$, os quais foram apenas ajustados aos valores da receita (3000 $\mathrm{mg} \mathrm{L}^{-1}$ de alcalinidade de 60 $\mathrm{mg} \mathrm{L}^{-1}$ de $\left.\mathrm{NaCl}\right)$.

\section{Controles analíticos}

\section{Caracterização dos banhos}

Antes e após o processo de tingimento, assim como após cada etapa do tratamento proposto, os banhos foram caracterizados por determinações de cor, demanda química de oxigênio, alcalinidade, cloretos e ferro solúvel. 
A cor foi avaliada espectrofotometricamente, utilizando-se espectrofotômetro HP 8452-A e cubetas de quartzo de $1 \mathrm{~cm}$. A cor foi expressa em termos de absorvância no(s) comprimento(s) de onda de máxima absorção ou como área espectral integrada entre 350 e 700 nm.

A demanda química de oxigênio (DQO) foi determinada de acordo com metodologia padrão (APHA: 5220D), ${ }^{22}$ fundamentada em digestão em tubo fechado seguida de determinação espectrofotométrica. Curvas analíticas foram elaboradas com padrão de biftalato de potássio, na faixa compreendida entre 100 e $800 \mathrm{mg} \mathrm{O}_{2} \mathrm{~L}^{-1}$. O desvio padrão típico desta determinação foi da ordem de $12 \%$.

A alcalinidade foi determinada de acordo com método padrão (APHA: 2320B), ${ }^{22}$ fundamentado em titulação ácido-base com padrão de ácido sulfúrico $\left(0,1 \mathrm{~mol} \mathrm{~L}^{-1}\right)$ até $\mathrm{pH} 4,5$. O resultado foi expresso em miligramas de $\mathrm{CaCO}_{3}$ por litro.

A determinação de cloreto foi realizada por potenciometria direta (APHA: 2580 B), ${ }^{22}$ utilizando-se eletrodo seletivo e potenciômetro Quimis. Curvas analíticas foram elaboradas com padrão de $\mathrm{NaCl}$, na faixa compreendida entre $5,0 \times 10^{-4}$ e $7,5 \times 10^{-2} \mathrm{~mol} \mathrm{~L}^{-1}$

O teor de ferro solúvel foi determinado espectrofotometricamente, utilizando-se procedimento padrão (APHA: 3500D) ${ }^{22}$ fundamentado na reação de ferro(II) com 1,10-fenantrolina. O teor de ferro(II) foi determinado diretamente, enquanto a concentração de ferro(III) foi determinada após a redução com hidroquinona. Curvas analíticas foram elaboradas com padrão de sulfato ferroso amoniacal, na faixa de concentração compreendida entre 0,4 e $4,0 \mathrm{mg} \mathrm{L}^{-1}$.

\section{Caracterização dos tecidos tintos}

A intensidade colorística (K/S) foi obtida a partir da equação de Kubelka-Munke (Equação 1), enquanto que a diferença de cor residual $(\Delta \mathrm{E})$ foi calculada a partir da expressão apresentada na Equação 2.

$$
\mathrm{K} / \mathrm{S}=(1-\mathrm{R})^{2} / 2 \mathrm{R}
$$

onde: $\mathrm{K}$ corresponde à absorção de luz pelo corante, $\mathrm{S}$ à medida da difusão da luz pelo substrato e R ao valor da remissão.

$$
\Delta \mathrm{E}=\left((\Delta \mathrm{H})^{2}+(\Delta \mathrm{C})^{2}+(\Delta \mathrm{L})^{2}\right)^{1 / 2}
$$

onde: $\Delta \mathrm{H}$ corresponde ao desvio de tonalidade, $\Delta \mathrm{C}$ ao desvio de pureza e $\Delta \mathrm{L}$ ao desvio de claridade.

Todos estes parâmetros foram determinados em espectrofotômetro de remissão Mathis, modelo Optronik.

Com a finalidade de avaliar a resistência dos corantes na fibra, diversos ensaios de solidez foram realizados, utilizando-se metodologias padrão e equipamentos especificamente destinados a este tipo de controle. Dentro deste contexto é possível destacar o índice de solidez à fricção (norma técnica NBR 8432), ${ }^{23}$ à lavagem (norma técnica NBR $13062)^{24}$ e ao suor ácido e alcalino (norma técnica NBR 8431). ${ }^{25}$

\section{RESULTADOS E DISCUSSÃO}

\section{Estudos preliminares envolvendo a degradação de corante modelo}

Inicialmente, inúmeros estudos foram realizados com o objetivo de verificar o efeito de variáveis operacionais de relevância (ex. espessura e massa da fibra de aço, $\mathrm{pH}$ da solução de corante e vazão de alimentação) na degradação de corantes azo por processos redutivos mediados por ferro metálico. De maneira geral, foi constatado que fibras de menor espessura favorecem o processo de degradação, basicamente em função da maior superfície disponível para ocorrência de reações redox. Por sua vez, o efeito do $\mathrm{pH}$ das amostras e da vazão de alimentação deve ser analisado com cautela, uma vez que baixos valores de $\mathrm{pH}$ e vazões reduzidas proporcionam elevada eficiência de degradação, ao mesmo tempo em que viabilizam a geração de elevadas concentrações de formas solúveis de ferro. Em condições de máxima eficiência de degradação, isto é, baixas vazões de alimentação, baixos valores de $\mathrm{pH}$ e mínima espessura das fibras de aço, a concentração de formas solúveis de ferro ultrapassa o valor de $50 \mathrm{mg}$ $\mathrm{L}^{-1}$, o que se mostra incompatível com o processamento de fibras de algodão, em função do dano catalítico causado por espécies férricas associadas a operações de lavagem com agentes branqueadores à base de peróxido. ${ }^{26}$

Em função destes argumentos, as condições de tratamento redutivo foram fixadas em $\mathrm{pH}$ 3, vazão de $15 \mathrm{~mL} \mathrm{~min}^{-1}$ e $14 \mathrm{~g}$ de lã de aço de menor espessura $(0,06 \mathrm{~mm})$. Nestas condições, a degradação do corante modelo (preto reativo 5) é bastante evidente (Figura 2), o que permite uma descoloração da ordem de $90 \%$, levando-se em consideração o decaimento do sinal registrado no comprimento de onda de absorção máxima (592 nm). Tipicamente, o processo de descoloração envolve a degradação redutiva do grupo cromóforo azo, com formação de derivados aminados característicos. ${ }^{21}$

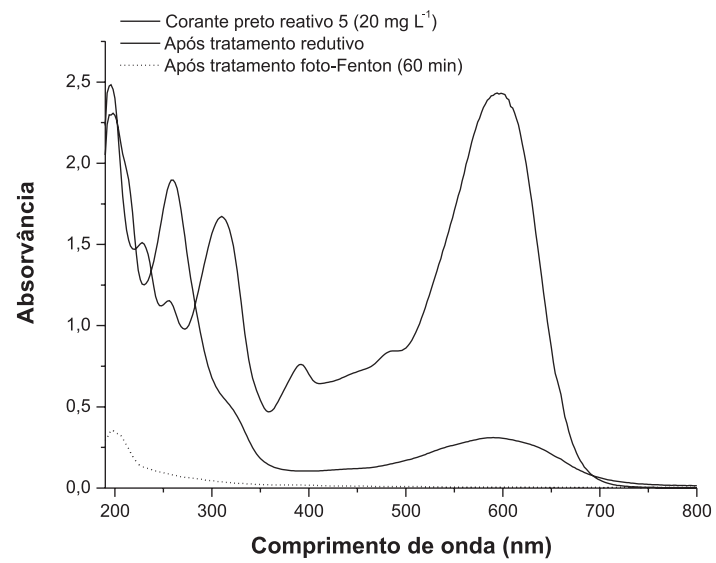

Figura 2. Modificação do perfil espectral do corante preto reativo 5 após tratamento redutivo (Corante: $20 \mathrm{mg} \mathrm{L}^{-1}$, pH: 3,0, vazão: $15 \mathrm{~mL} \mathrm{~min}^{-1}$, massa de lã de aço: $12 \mathrm{~g}$ ) e oxidativo ( $\mathrm{pH}: 3,0, \mathrm{Fe}^{2+}: 8 \mathrm{mg} \mathrm{L}^{-1} ; \mathrm{H}_{2} \mathrm{O}_{2}: 100 \mathrm{mg} \mathrm{L}^{-1}$ )

A permanência de intensos sinais na região ultravioleta (Figura 2), característicos de grupos aromáticos substituídos, demonstra uma capacidade de mineralização praticamente nula do sistema redutivo, o que aponta para a necessidade de processos oxidativos auxiliares. A este respeito, é importante salientar que a geração de formas solúveis de ferro(II), em concentrações entre 5 e $10 \mathrm{mg} \mathrm{L}^{-1}$, viabiliza a posterior aplicação de processos Fenton, o que corresponde à principal proposta deste trabalho.

A aplicação de processos foto-Fenton foi viabilizada pela adição de peróxido de hidrogênio, em concentração final de $100 \mathrm{mg} \mathrm{L}^{-1}$. De maneira geral, tratamentos de 60 min permitiram a completa remoção da cor residual das amostras, assim como uma significativa remoção dos fragmentos que absorvem na região ultravioleta (Figura 2). O pequeno sinal residual centrado em $200 \mathrm{~nm}$ pode ser devido à presença de ácidos orgânicos, principalmente ácido oxálico, espécies que costumam se acumular no final do processo. ${ }^{27}$

Em razão do processo foto-Fenton ter sido aplicado em $\mathrm{pH}$ próximo de 3 e de ter envolvido concentrações relativamente baixas de ferro solúvel (5 a $\left.10 \mathrm{mg} \mathrm{L}^{-1}\right)$, a precipitação de óxidos férricos não foi observada durante o tratamento. Entretanto, a formação deste tipo de precipitados é bastante comum em processos que envolvem o uso de formas férricas, o que normalmente obriga à aplicação de processos adicionais orientados à sua remoção. Em geral, este tipo de precipitado pode ser removido com facilidade por processos de 
coagulação química seguida de decantação, processo este que, sendo parte de praticamente toda rotina de tratamento da indústria têxtil, não acrescentaria custos adicionais de relevância.

\section{Estudos de degradação dos banhos de tingimento}

Após tingimento, os banhos residuais foram tratados pela rotina redutiva-oxidativa proposta neste estudo, obtendo-se os resultados apresentados na Figura 3. De acordo com estes resultados, o processo redutivo induz uma significativa redução na cor do efluente, o que se manifesta como redução de absorvância da ordem de $85 \%$ no comprimento de onda de máxima absorção $(540 \mathrm{~nm})$. Na região ultravioleta, os sinais se modificam sensivelmente. Entretanto, o forte sinal observado entre 210 e $230 \mathrm{~nm}$ atesta a presença de espécies aromáticas, resistentes a este tipo de tratamento. No processo redutivo a concentração de matéria orgânica (medida em termos de DQO) é reduzida a praticamente à metade do valor original, provavelmente por conta da coprecipitação em partículas de óxido férrico, produzidas pela corrosão das fibras de aço.

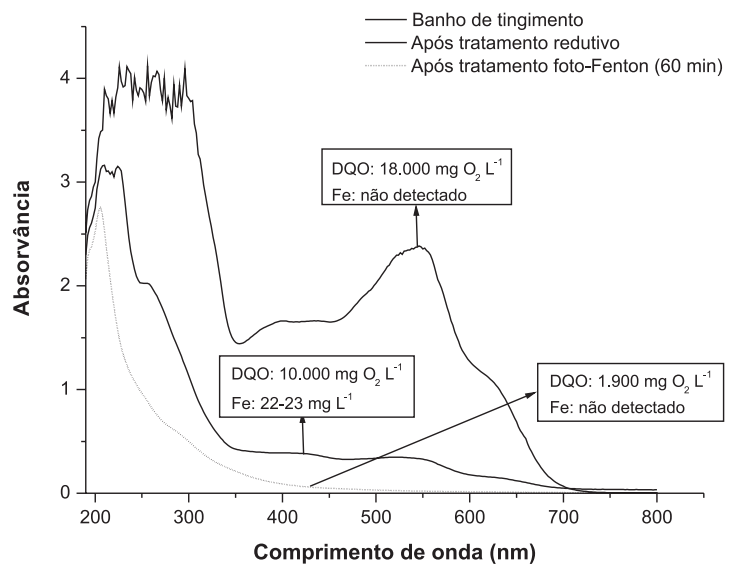

Figura 3. Modificação do perfil espectral do banho de tingimento após tratamento redutivo ( $\mathrm{pH}: 3,0$, vazão: $15 \mathrm{~mL} \mathrm{~min} \mathrm{~m}^{-1}$, massa de lã de aço: $12 \mathrm{~g}$ ) e oxidativo ( $\mathrm{pH}: 3,0, \mathrm{Fe}^{2+}: 10 \mathrm{mg} \mathrm{L}^{-1} ; \mathrm{H}_{2} \mathrm{O}_{2}: 100 \mathrm{mg} \mathrm{L}^{-1}$ )

Por sua vez, o processo foto-Fenton permitiu a completa remoção da cor residual, assim como uma significativa remoção dos sinais característicos de espécies aromáticas. Neste tratamento sequencial, a DQO foi reduzida em aproximadamente $90 \%$, o que atesta o avançado grau de degradação que o processo permite.

A sequência de tratamento provocou, adicionalmente, uma significativa redução da alcalinidade dos banhos, parâmetro que alcançou valores da ordem de $100 \mathrm{mg} \mathrm{L}^{-1}$. Por sua vez, o teor de cloreto alcançou valores da ordem de $43 \mathrm{mg} \mathrm{L}^{-1}$.

\section{Reuso dos banhos tratados}

A água tratada pelo processo proposto foi utilizada em novos processos de tingimento, os quais foram identificados como reuso 1 e 2, como explicado anteriormente. Para comparação, um tingimento padrão foi realizado em paralelo, com água destilada.

O primeiro parâmetro relevante a ser investigado nos estudos de reuso está representado pela avaliação da transferência dos corantes para a fibra têxtil (esgotamento). Nos resultados apresentados na Tabela 1 é possível observar que tanto em condições de tingimento padrão (água destilada), como nos ensaios envolvendo o reuso da água tratada, a transferência dos corantes para a fibra de algodão alcança valores superiores a 99\%. Pelo menos em primeira análise, este resultado sugere uma elevada eficiência de tingimento e, portanto, a viabilidade do reuso após o tratamento proposto. Adicionalmente, é possível observar que ambas estratégias adotadas em relação aos parâmetros de alcalinidade e teor de cloretos (reuso 1: adição das quantidades previstas na receita; reuso 2: ajuste das concentrações aos valores da receita) são equivalentes, proporcionando resultados bastante similares. Finalmente, a grande semelhança observada nos resultados dos reusos 1 e 2 atesta a boa repetibilidade do processo de tingimento, o que, consequentemente, atesta uma boa repetibilidade do sistema de tratamento proposto.

Tabela 1. Exaustão dos corantes e principais características dos tecidos tintos obtidos nos estudos de reuso

\begin{tabular}{lccc}
\hline Tingimento & $\begin{array}{c}\text { Exaustão dos } \\
\text { corantes }(\%)\end{array}$ & K/S & $\begin{array}{c}\Delta \mathrm{E} \\
\text { (Diferença de cor) }\end{array}$ \\
\hline Padrão & $>99$ & 12,06 & - \\
Reuso 1 & $>99$ & 13,59 & 1,94 \\
Reuso 2 & $>99$ & 12,90 & 1,67 \\
\hline
\end{tabular}

Como comentado anteriormente, o processo redutivo/oxidativo induz uma eficiente degradação da matéria orgânica, o que permite uma redução de cerca de $90 \%$ no teor de DQO. Embora a DQO residual seja de aproximadamente $2000 \mathrm{mg} \mathrm{L}^{-1}$, provavelmente em decorrência de fragmentos moleculares que se acumulam no final do processo, não foi observada uma significativa influência deste teor residual no processo de tingimento, haja vista a boa qualidade dos tecidos tintos pelas rotinas de reuso.

É importante salientar que grande parte do custo associado ao processo proposto está representada pela necessidade de fontes artificiais de radiação. Recentemente, um equipamento para tratamento contínuo de resíduos foi desenvolvido, o qual, operando com 4 lâmpadas a vapor de mercúrio de $125 \mathrm{~W}$, permite o tratamento de aproximadamente $1 \mathrm{~m}^{3}$ de resíduo em $8 \mathrm{~h}$ de operação. Nestas condições, o custo energético é equivalente ao consumo de 4 lâmpadas de iluminação pública, o que corresponde a valores inferiores a $\mathrm{R} \$ 1,00$.

Nas condições em que referido equipamento funciona (vazão de $2 \mathrm{~L} \mathrm{~min}^{-1}$ ), o tempo de retenção não ultrapassa $10 \mathrm{~min}$. Portanto, a prática de tempos da ordem de $1 \mathrm{~h}$ implicaria na necessidade de ampliação de escala, a qual pode ser viabilizada pelo uso de lâmpadas de $250 \mathrm{~W}$. Obviamente que, neste caso, o custo do tratamento aumenta proporcionalmente.

\section{Análise colorimétrica dos substratos}

Após tingimento, os tecidos foram secos a temperatura ambiente e analisados por espectrofotometria de remissão, medindo-se os parâmetros de intensidade colorística (K/S) e diferença de cor residual $(\Delta \mathrm{E})$. Os resultados (Tabela 1$)$ indicam valores de intensidade colorística $(\mathrm{K} / \mathrm{S})$ bastante próximos, com diferenças inferiores ao desvio padrão observado nas medições em replicata $(0,77)$. Esta similaridade atesta a qualidade do tingimento realizado com água tratada.

Os valores de diferença de cor $(\Delta \mathrm{E})$, em relação ao tingimento padrão, são também apresentados na Tabela 1. De maneira geral, esta avaliação reproduz a percepção do olho humano, o qual consegue distinguir diferenças de cor equivalentes a $\Delta \mathrm{E}$ de 0,2 . De acordo com a norma específica (norma DIN 6174,1979), ${ }^{28}$ valores de $\Delta$ E entre 1,5 e 3,0 correspondem a diferenças distinguíveis, de maneira geral não aceitas para a produção de tecidos destinados à importação $(\Delta \mathrm{E} 1,0)$. Entretanto, valores de $\Delta \mathrm{E}$ inferiores a 2,0 costumam ser considerados satisfatórios por empresas menos exigentes, principalmente quando os produtos são comercializados no mercado nacional.

A diferença de cor referida (Figura $1 \mathrm{~S}$, material suplementar) pode ser devida à interferência de algum subproduto gerado durante 
Tabela 2. Resultados da avaliação da solidez da cor nos tecidos tintos, em relação à fricção, lavagem e suor

\begin{tabular}{|c|c|c|c|c|c|c|c|c|}
\hline \multirow{2}{*}{ Tingimento } & \multicolumn{2}{|c|}{ Fricção } & \multicolumn{2}{|c|}{ Lavagem } & \multicolumn{2}{|c|}{ Suor ácido } & \multicolumn{2}{|c|}{ Suor alcalino } \\
\hline & Seco & Úmido & Transferência & Substrato & Transferência & Alteração & Transferência & Alteração \\
\hline Padrão & 5,0 & 4,5 & 4,5 & 4,5 & 5,0 & 4,5 & 5,0 & 4,5 \\
\hline Reuso 1 & 5,0 & 4,5 & 4,5 & 4,0 & 5,0 & 4,5 & 5,0 & 4,5 \\
\hline Reuso 2 & 5,0 & 4,5 & 4,5 & 4,0 & 5,0 & 4,5 & 5,0 & 4,5 \\
\hline
\end{tabular}

o processo de degradação. Entretanto, são necessários estudos complementares para elucidar este fato.

Os resultados de solidez da cor em relação à fricção (em seco e úmido), à lavagem e ao suor ácido e alcalino são apresentados na Tabela 2. Em razão dos valores apresentados pelos tecidos tingidos nas operações de reuso serem exatamente os mesmos que os apresentados pelo tecido tingido de acordo com a receita padrão, pode-se concluir que o reuso do efluente tratado permite uma fixação comparável àquela permitida pelo tingimento padrão.

Finalmente, é importante salientar que a DQO residual observada após cada ciclo de tratamento (entre 1500 e $2000 \mathrm{mg} \mathrm{L}^{-1}$ ) limita o número de ciclos de reuso, característica esta que depende, ainda, do tipo de cor utilizada no processo de tingimento. De maneira geral, observou-se que o tingimento com cores claras permite somente dois ciclos de reuso, enquanto que o tingimento com cores escuras, menos sensível à DQO residual, permite a realização de pelo menos quatro ciclos de reuso.

\section{CONCLUSÕES}

Processos redutivos, aplicados na forma de tratamento contínuo e na presença de lã de aço, permitem uma eficiente degradação de corantes em solução aquosa, o que permite uma eficiente remoção da cor (aproximadamente 90\%), assim como a geração de íons ferrosos em concentração compatível com a aplicação subsequente de processos foto-Fenton ( 5 a $\left.10 \mathrm{mg} \mathrm{L}^{-1}\right)$. No processo foto-Fenton subsequente a cor residual é completamente removida, ao mesmo tempo em que a DQO é reduzida até valores da ordem de $10 \%$.

$\mathrm{O}$ reuso das águas tratadas em novos processos de tingimento permitiu a obtenção de tecidos que atendem a praticamente todas as exigências da indústria. Exceção feita, somente, ao parâmetro de diferença de cor, que se apresenta elevado em relação aos padrões de importação, mas adequado para atendimento do mercado nacional.

\section{MATERIAL SUPLEMENTAR}

Encontra-se disponível em http://quimicanova.sbq.org.br na forma de arquivo .PDF, com acesso livre. Na Figura $1 \mathrm{~S}$ apresenta-se uma fotografia dos tecidos tingidos por procedimento padrão e por ensaios de reuso.

\section{AGRADECIMENTOS}

Ao Laboratório Têxtil do Departamento de Química da Fundação Universidade Regional de Blumenau, pela disponibilização de infraestrutura para realização dos ensaios de tingimento, e ao Conselho Nacional de Desenvolvimento Científico e Tecnológico (CNPq) pelo suporte financeiro (Processo No 474066/2006-1).

\section{REFERÊNCIAS}

1. Mohan, N.; Balasubramanian, N.; Basha, C. A.; J. Hazard. Mat. 2007, 147, 644.

2. Brik, M.; Schoeberl, P.; Chamam, B.; Braun, R.; Fuchs, W.; Process Biochem. 2006, 41, 1751.

3. Capar. G.; Yilmaz, L.; Yetis, U.; Hazard. Mat. 2008, 152, 316.

4. Radha, K. V.; Sridevi, V.; Kalaivani, K.; Bioresource Technol. 2000, 100, 987.

5. Khaled, A.; El Nemr, A.; El-Sikaily, A.; Abdelwahab, O.; Desalination 2009, 238, 210.

6. Ertuğrul, S.; San, N. O.; Dönmez, G.; Ecological Eng. 2009, 35, 128.

7. Harrelkas, F.; Paulo, A.; Alves, M. M.; El Khadir, L.; Zahraa, O.; Pons, M. N.; van der Zee, F. P.; Chemosphere 2008, 72, 1816.

8. Rajkumar, D.; Kim. J. G.; J. Hazard. Mat. 2006, 136, 203.

9. Fersi, C.; Dhahbi, M.; Desalination 2008, 222, 263.

10. Sahinkaya, E.; Uzal, N.; Yetis, U.; Dilek, F. B.; J. Hazard. Mat. 2008, $153,1142$.

11. Lin, S. H.; Chen, M. L.; Water Res. 1997, 31, 868.

12. Dhodapkar, R. S.; Pophali, G. R.; Nandy, T.; Devotta, S.; Mohan, N.; Balasubramanian, N.; Basha, C. A.; Desalination 2007, 217, 291.

13. Papadopoulos, A. E.; Fatta, D.; Loizidou, M.; J. Hazard. Mat. 2007, 146, 558.

14. Dantas, T. L. P.; Mendonça, V. P.; José, H. J.; Rodrigues, A. E.; Moreira, R. F. P. M.; J. Chem. Eng. 2006, 118, 77.

15. Montserrat, P.; Torrades, F.; Domènech, X.; Peral, J.; Water Res. 2002, 36, 2703.

16. Shyh-Fang, K.; Chih-Hsiang, L.; Shei-Tue P.; Chemosphere 2000, 41, 1287.

17. Üstün, G. E.; Solmaz, K. A. S.; Birgül, A.; Resources, Conservation and Recycling 2007, 52, 425.

18. Ince, N. H.; Tezcanlı G.; Water Sci. Technol. 1999, 40, 183.

19. Lin, H. S.; Chen, M. L.; Desalination 1997, 109, 121.

20. Bigg, T.; Judd, S. J.; Process Saf. Environ. Protect. 2001, 79, 297.

21. Devi, L. G.; Kumar, S. G.; Reddy, K. M.; Munikrishnappa, C.; J. Hazard. Mat. 2009, 164, 459.

22. APHA; Standard Methods for Examination of Water and Wastewater (APHA, AWWA), 20 th ed., WPCF: New York, 2000.

23. Associação Brasileira de Normas Técnicas; NBR 8432: Determinação de solidez de cor à fricção, Associação Brasileira de Normas Técnicas: São Paulo, 1984.

24. Associação Brasileira de Normas Técnicas; NBR 13062: Determinação de solidez de cor à lavagem. Ensaio $n^{0} 3$; Associação Brasileira de Normas Técnicas: São Paulo, 1994.

25. Associação Brasileira de Normas Técnicas; NBR 8431: Materiais Têxteis - Determinação da solidez da cor ao suor, Associação Brasileira de Normas Técnicas: São Paulo, 1984.

26. Kongdee, A.; Bechtold, T. Carbohydr. Polym. 2004, 56, 4.

27. Du, Y.; Zhou, M.; Lei, L.; Water Res. 2007, 41, 1121.

28. DIN - Deutsche Institut für Normung; DIN 6174. Farbmetrische Bestimmung Von Farbabständen bei Körperfarben nach der CIELAB- Formel, Beuth Verlag, Berlim und Köln, 1979. 
TRATAMENTO DE BANHOS DE TINGIMENTO TÊXTIL POR PROCESSOS FOTO-FENTON E AVALIAÇÃO DA POTENCIALIDADE DE REUSO

Geovani Zanella, Mauro Scharf e Giovana Aparecida Vieira

Departamento de Química, Fundação Universidade Regional de Blumenau, 89012-900 Blumenau - SC, Brasil

Patricio Peralta-Zamora*

Departamento de Química, Universidade Federal do Paraná, CP 19081, 81531-980 Curitiba - PR, Brasil

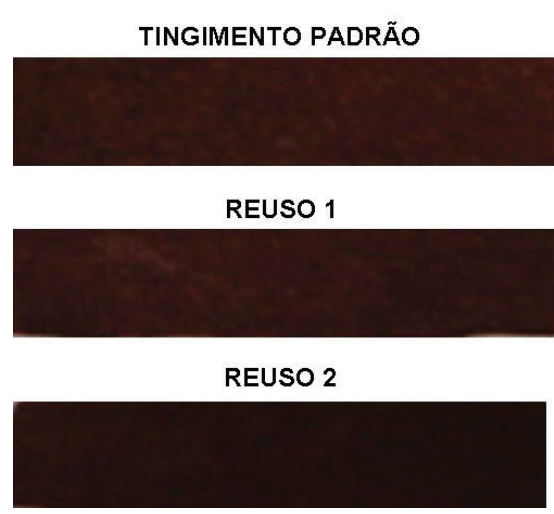

Figura 1S. Fotografia dos tecidos tingidos por procedimento padrão e por ensaios de reuso 